\title{
Respiratory health and indoor air pollutants based on quantitative exposure
} assessments

\author{
Marion Hulin**\#, Marzia Simoni ${ }^{\top}$, Giovanni Viegi ${ }^{\uparrow,+}$ and Isabella Annesi-Maesano*,\#
}

ABSTRACT: We reviewed the main epidemiological studies that evaluate the respiratory effects of indoor air pollutants quantitatively in industrialised countries. Consistent results support short-term (aggravation) and, although more rarely, long-term (prevalence augmentation) effects on asthma, chronic bronchitis and chronic obstructive pulmonary disease (COPD) in indoor settings with poor air quality. Environmental tobacco smoke is one of the most important risks for respiratory symptoms and diseases worldwide. The evidence is also reliable for indoor nitrogen dioxide and particulate matter, which have been associated with asthma, bronchitis and COPD. Whereas formaldehyde and volatile organic compounds seem to be the main pollutants in indoor settings, relevant papers on their respiratory effects are still scarce, and limited to asthma and bronchitis. Moulds have been associated with an increased risk of asthma and COPD. Contradictory results have been found between endotoxins and asthma. The role of phthalates, persistent organic pollutants and flame retardants in respiratory diseases remains to be established. Results from rural areas of industrialised countries indicate that exposure to some indoor bio-contaminants might be protective in early life, while it is associated with adverse respiratory adverse effects in adulthood. Studies focusing on indoor air pollutants should be developed to better understand their involvement in the inception and aggravation of respiratory diseases.

KEYWORDS: Air pollution, asthma, dwellings, indoor, respiratory health

$\mathbf{U}$ ntil a few years ago, most investigations on the health effects of air pollution focused on outdoor air pollutants. Strong evidence exists that such pollutants, mainly from road traffic in recent decades, adversely affect respiratory health [1]. Since then, concern over the health effects of indoor air pollution has increased. People spend as much as $90 \%$ of their time in confined environments, especially at home, and the concentrations of some air pollutants may be two- to five-fold higher indoors than outdoors. Lastly, improvement of thermal insulation, in order to reduce heat loss, and scarce ventilation in modern dwellings lead to deterioration of indoor air quality (IAQ) [2]. Poor IAQ poses a risk to the health of over half of the world's population, especially affecting poor people. Indoor air pollution is the eighth most important risk factor, being responsible for $2.7 \%$ of the global burden of disease (between 1.5 and 2 million deaths yearly) [3]. Among disorders associated with poor IAQ, respiratory diseases are important as inhalation is the major pathway for air pollutants. Previous studies have reported significant associations between asthma symptoms and indoor sources of chemical pollutants, materials or activities, such as recent painting or new wall covering, volatile organic compounds (VOCs), gas appliances, or exposure to particles through environmental tobacco smoke (ETS) or heating appliances using wood/coal. However, the lack of data obtained by objective assessments limit the determination of the air pollutants that are actually responsible for the observed respiratory effects. Indeed, although the presence of sources of indoor

Previous articles in this series: No. 1: Kurmi OP, Lam KBH, Ayres JG. Indoor air pollution and the lung in low- and medium-income countries. Eur Respir $J$ 2012; 40: 239-254

This article has supplementary material available from www.erj.ersjournals.com

AFFILIATIONS

*INSERM, UMR 707, EPAR,

\#UPMC Univ Paris 06, UMR S 707

EPAR, Paris, France.

'Pulmonary Environmental

Epidemiology Unit, CNR Institute of

Clinical Physiology, Pisa, and

${ }^{+}$CNR Institute of Biomedicine and

Molecular Immunology "A. Monroy",

Palermo, Italy.

CORRESPONDENCE

I. Annesi-Maesano

Epidemiology of Allergic and

Respiratory Diseases (EPAR), UMR S 707, INSERM-UPMC-Paris 6

Medical school St Antoine

27 rue de Chaligny

75571 Paris Cedex 12

France

E-mail: isabella.annesi-maesano@

inserm.tr

Received:

Sept 132011

Accepted after revision:

June 112012

First published online:

July 122012 
pollution may be a good proxy of exposure, quantitative measurement-based exposure assessments may be more useful for assessing the health effects of exposure, understanding the underlying mechanisms and for implementing preventative policies in terms of standards and guidelines.

Our aim was to review the main population-based studies that evaluate the respiratory effects (mainly asthma, chronic bronchitis and chronic obstructive pulmonary disease (COPD)) of quantitatively measured indoor air pollutants in industrialised countries.

\section{METHODS}

For the purpose of the present review, we summarised papers published in English in peer-reviewed journals on the associations between major indoor air pollutants and respiratory outcomes, in people of all ages living in high-income (westernised) countries, that simultaneously reported data on objectively quantitative assessments of indoor air pollutants ("existing concentrations/levels") and documented asthma, chronic bronchitis or COPD. More precisely, the following MeSH terms were used to search the PubMed database up to the year 2011: "indoor(s)" and "levels (concentrations)" of " $\mathrm{NO}_{2}$ " / "Particulate Matter (PM)" /"volatile organic compounds (VOCs)" /"formaldehyde (FA)" /"phthalates"/"persistent organic pollutants (POPs)" / "flame retardants (FRs)" /"allergen"/"endotoxin"/ "moulds" as well as "sources of indoor air pollution" as risk factors and "asthma" / "COPD" / "chronic bronchitis", as respiratory health outcomes. Overall, there were 29 articles for $\mathrm{NO}_{2}, 24$ for PM, 11 for VOCs, 42 for FA, 11 for phthalates, 708 for allergens, 53 for endotoxins, 173 for moulds and 12 for POPs and flame retardants. Only the articles that reported populationbased data were included in the present systematic review.

\section{INDOOR AIR POLLUTANTS AND RELATIVE SOURCES}

Epidemiological studies on respiratory health have mainly assessed the effects of exposure to bio-contaminants, such as allergens, moulds and endotoxins, and chemical air pollutants, such as nitrogen dioxide, particulate matter, formaldehyde and VOCs. Figure 1 shows the main indoor air pollutants and related sources.
Indoor allergens mainly originate from house dust mite (HDM), furred pets (primarily cat and dog dander), insects (cockroaches), moulds and, to a lesser extent, plants and rodents. The most common species of HDM living in Europe are Dermatophagoides pteronyssimus and Dermatophagoides farinae; allergens Der $\mathrm{p} 1$ and Der $\mathrm{f} 1$, respectively, are proteolytic enzymes present in their bodies and faeces. The mostly studied species of cockroaches are Periplaneta americana, Blattella germanica and Blatta orientalis; allergens can be produced by dead bodies and faecal matter. Hundreds of mould species are found indoors. Common genera are Alternaria, Cladosporium, Aspergillus, Penicillium and Fusarium [4]. The presence of water, nutrients or elevated temperature facilitates the proliferation of moulds, cockroaches and mites, thus increasing the concentration of allergens. Major sources of mould growth indoors are flood, leaks in building fabric, condensation, unattended plumbing leaks and household mould. Endotoxins are components of the outer membrane of various Gram-negative bacteria. Several sources of endotoxins have been suggested, such as contaminated humidifiers, pet keeping and contact with livestock, or storage of food waste.

There are more chemical pollutants indoors than outdoors: they stem from outdoor-indoor transfers or specific indoor sources. The European Commission Scientific Committee on Health and Environmental Risks (SCHER) reports that >900 different compounds have been detected indoors [5]. Most indoor pollutants derive from anthropogenic activity (combustion processes, redecorating/remodelling/repair or cleaning activity).

Nitrogen dioxide and particulate matter are common air pollutants both indoors and outdoors. Indoors, they can be generated by tobacco smoking, the use of devices running on gas, kerosene, wood or coal, and, to a lesser extent, by cleaning and renovation activities. In developing nations, biomass fuel (wood, charcoal, dung, etc.) is frequently burned in households in open fires or inefficient stoves. The consequence is a large production of substances harmful to health derived from incomplete combustion, including particulate matter, carbon monoxide, nitrogen oxides and polycyclic aromatic hydrocarbons (PAHs). In houses where biomass fuels are used, particulate matter levels may be 10-50 times higher than the
Sources

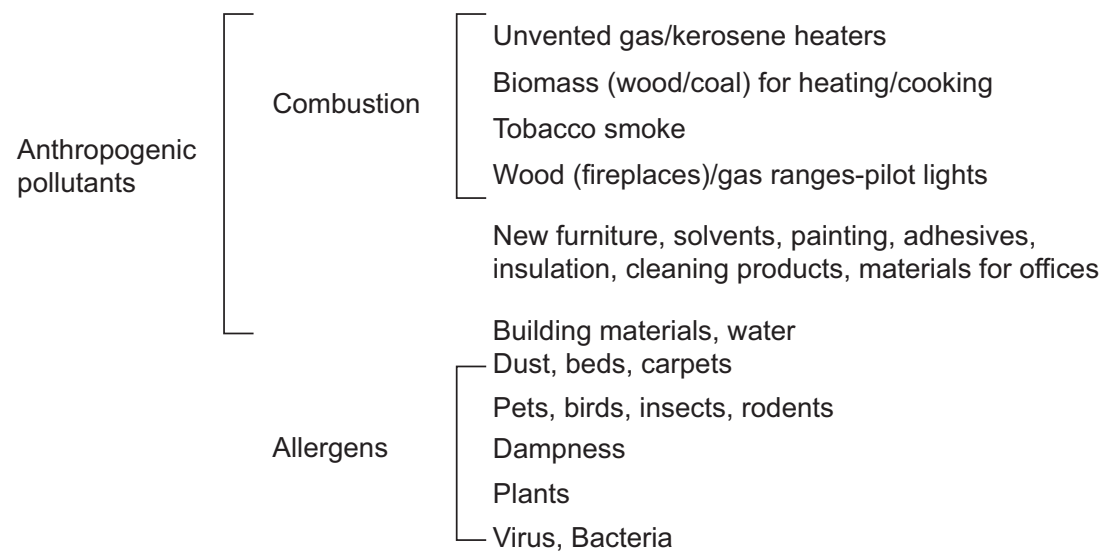

Pollutants

$$
\begin{aligned}
& \mathrm{CO}, \mathrm{CO}_{2}, \mathrm{NO}_{2}, \mathrm{PAHs} \\
& \mathrm{CO}, \mathrm{CO}_{2}, \mathrm{PM}, \text { PAHs } \\
& \mathrm{CO}, \mathrm{CO}_{2}, \mathrm{PM}, \text { VOCs, PAHs } \\
& \text { VOCs }
\end{aligned}
$$

VOCs, formaldehyde

Radon

Acarides (HDM)

Moulds

Pollens

Biological contaminants

FIGURE 1. Main indoor pollutants and related sources. PAH: polycyclic aromatic hydrocarbon; PM: particulate matter; VOC: volatile organic compound; HDM: house dust mite. 
guideline values for good IAQ. About 3 billion people (almost half of humanity) rely on solid fuels for cooking/heating, with little or no access to modern forms of energy [6]. The World Health Organization (WHO) reports that, globally, $\sim 1.5$ billion people have no access to electricity, and $>80 \%$ of them live in sub-Saharan Africa and South Asia [7]. Only 27\% of people relying on solid fuels use improved cooking stoves. Biomass fuels are much more commonly used in rural than in urban areas. The exposure to biomass fuels is strongly povertyrelated and, consequently, is a major health concern in the developing world, especially for children and females, who generally spend much time in the kitchen for cooking.

One of the major sources of indoor air pollution is tobacco smoke. It contains $>4,500$ compounds. Out of them, $\geqslant 250$ chemicals are known to be toxic and $>50$ can cause cancer [8]. In indoor environments where people smoke, tobacco smoke is the major source of particulate matter.

Formaldehyde is another hazardous pollutant principally found indoors. It is mainly produced by off-gassing from wood-based products assembled using urea-formaldehyde resins but can also be generated by cigarette smoking, painting, or the use of varnishes and floor finishes $[9,10]$. VOCs are chemical compounds including aromatic hydrocarbons, aldehydes, aliphatic halogenated hydrocarbons and terpenes.

Recently, there is new interest in phthalates, a group of chemicals added to plastic materials to make them soft and flexible that can be found on surfaces and in the air. Their many uses lead to multiple routes of exposure, including inhalation, thus representing a potential risk for respiratory health. The major source of phthalates in the average home is most likely vinyl flooring. Emerging indoor pollutants include also persistent organic pollutants (POPs) and flame retardants, which are potentially hazardous for respiratory organs because they can be inhaled. POPs are organic compounds that are resistant to environmental degradation. They have been observed to be capable of bioaccumulating in human and animal tissue, and to have potential significant impacts on human health and the environment. POPs are employed in pesticides, solvents, polyvinyl chloride and pharmaceuticals. Of the commercialised chemical flame retardants, brominated flame retardants (BFRs) are most widely used as a mean of reducing the flammability of the products in plastics and textile applications, e.g. electronics, clothes and furniture.

\section{GEOGRAPHICAL VARIATIONS IN IAQ IN INDUSTRIALISED COUNTRIES}

Differences in cultural habits of people throughout the world result in large quantitative and qualitative differences in IAQ. Nowadays, a large number of studies include measurements of indoor pollution; however, they have often focused on a local or regional geographical zone. National studies have now been conducted in industrialised countries in order to obtain representative data of indoor exposure to biological and chemical air pollutants at the population level.

Quantity or concentrations of allergens and endotoxin are mainly assessed in reservoir samples such as mattresses, carpets, sofas and other furnishings by collecting dust with a vacuum cleaner. It has been estimated in a national survey including 831 representative housing units in 75 locations throughout the USA that $52 \%$ of homes had at least six detectable allergens and $4 \%$ had at least high concentrations of three allergens [11]. In France, the "dwellings" campaign, conducted by the Observatory on Indoor Air Quality in 567 representative houses, showed that $50 \%$ of homes had concentrations of cat and dog allergens higher than quantification levels; the same proportion had HDM allergens concentrations higher than the threshold level for risk of sensitisation proposed at $2 \mu \mathrm{g} \cdot \mathrm{g}^{-1}$ of dust [12]. Data for the European Community Respiratory Health Survey (ECRHS) showed that across Europe, Der 1 and Der 2 allergens were detectable $\left(\geqslant 0.1 \mu \mathrm{g} \cdot \mathrm{g}^{-1}\right)$ in $68 \%$ and $53 \%$ of the samples, respectively [13]. Large differences in allergen levels between study centres were observed, and geographic patterns for Der $p$ 1 and Der $\mathrm{f} 1$ were different. Low winter temperatures reduced Der $\mathrm{p} 1$ rather than Der $\mathrm{f} 1$. Important risk factors for high allergen levels included an older mattress, a lower floor level of the bedroom, limited ventilation of the bedroom, and dampness for Der $\mathrm{p} 1$ but not for Der $\mathrm{f} 1$. The same survey on the basis of quantitative cat allergen assessments found that people who do not own cats may be exposed to high levels of cat allergen in their home, particularly if they live in communities with high levels of cat ownership [14]. Endotoxin is ubiquitous in the environment, with higher concentrations in occupational settings (frequently $\left.>100 \mathrm{ng} \cdot \mathrm{m}^{-3}\right)$ than in the home $\left(<1 \mathrm{ng} \cdot \mathrm{m}^{-3}\right)$. In the US NSLAH (National Survey of Lead and Allergens in Housing), weighted geometric mean endotoxin concentration ranged from 18.7 to 80.5 endotoxin units $(\mathrm{EU}) \cdot \mathrm{mg}^{-1}$ for the five sampling locations, and endotoxin load ranged from 4,160 to $19,500 \mathrm{EU} \cdot \mathrm{m}^{-2}$ [15]. In Europe, the median endotoxin concentration in mattress dust collected in the ECRHS ranged from $772 \mathrm{EU} \cdot \mathrm{g}^{-1}$ dust in Reykjavik, Iceland, to $4,806 \mathrm{EU} \cdot \mathrm{g}^{-1}$ in Turin, Italy. High average outdoor summer temperature of the study centre, cat or dog keeping, a high household crowding index, and visible damp patches in the bedroom were significantly associated with higher endotoxin concentrations in mattress dust [16]. At the population level, exposure to moulds is mainly based on visual detection by inhabitants or technicians. It has been estimated, based on several European countries, the USA and Canada, that $\geqslant 20 \%$ of buildings have one or more signs of dampness [17]. This prevalence can vary among countries. In a study conducted in Iceland, Norway, Sweden, Denmark and Estonia, $18 \%$ of houses presented indoor dampness [18], whereas in the USA, $\sim 50 \%$ of the dwellings had dampness and/or fungi [19]. However, it has been shown that such qualitative methods can lead to an underestimation of mould exposure [20, 21]. The use of quantitative methods, based on fungal colony counts or mould marker assessment, is more and more used, but reliability of such methods is questioned.

Chemical pollution can be assessed by active or passive air samplers (active for particulate matter, passive for nitrogen dioxide, and both for VOCs and formaldehyde). The EXPOLIS (Exposure Distribution of Adult Urban Populations) study assessed indoor (in both dwellings and working places) and outdoor concentrations of different pollutants (fine particles, VOCs, nitrogen dioxide and carbon monoxide) in seven European cities [22-24]. Mean indoor concentrations of fine particles (particles with a 50\% aerodynamic cut-off diameter of $2.5 \mu \mathrm{m} ; \mathrm{PM} 2.5)$ or nitrogen dioxide were two to three times lower in Helsinki, Finland, than in Prague, Czech Republic (12.1 versus 35.9 and 24 versus $61 \mu \mathrm{g} \cdot \mathrm{m}^{-3}$, respectively) and up to six times 
lower for benzene between Helsinki and Milan, Italy (2.2 versus $13.2 \mu \mathrm{g} \cdot \mathrm{m}^{-3}$, respectively). In GerES II (German Environmental Survey II), conducted in 502 German dwellings [25-27], the median concentration of formaldehyde was $70 \mu \mathrm{g} \cdot \mathrm{m}^{-3}$, but even concentrations up to $816 \mu \mathrm{g} \cdot \mathrm{m}^{-3}$ have been measured. In the Survey of English Housing, performed in the UK, the median concentration in the 833 bedrooms was $24.0 \mu \mathrm{g} \cdot \mathrm{m}^{-3}$ with a maximum value of $171 \mu \mathrm{g} \cdot \mathrm{m}^{-3}$ [28]. In France, in the OQAI sample of 567 homes, it has been estimated that the median concentration of formaldehyde was $19.6 \mu \mathrm{g} \cdot \mathrm{m}^{-3}$ with a maximum value of $86.3 \mu \mathrm{g} \cdot \mathrm{m}^{-3}$ [29]. Similar differences could be found for the majority of pollutants. Such results were also observed in US studies, such as the National Human Exposure Assessment Survey [30], as well as in the numerous international and national epidemiological studies focusing on the health effects of indoor pollution. Recently, LOGUE et al. [31] calculated mid-range and upper bound concentrations relevant to chronic exposure to 267 pollutants. By compiling results from 77 published studies reporting measurements of chemical pollutants in the USA and in countries with similar lifestyles, they estimated that median concentrations of nitrogen dioxide, PM2.5, formaldehyde and benzene were $16.2,15.7,23$ and $2.1 \mu \mathrm{g} \cdot \mathrm{m}^{-3}$, with concentrations up to $144.2,86.0,10$ and $99 \mu \mathrm{g} \cdot \mathrm{m}^{-3}$, respectively. Similar concentrations were found in offices or schools [32-35]. In developing or emerging countries, compared with industrialised ones, higher indoor concentrations are often observed [3], in particular for nitrogen dioxide and PM2.5, due to differences in cooking and heating habits (see section on rural areas).

Important variations can be observed between dwellings but also inside dwellings due to spatio-temporal variations. IAQ is indeed determined by a number of factors, including type and emission rates from sources, as well as ventilation rate, adsorption and absorption of compounds on/in materials. Concentrations of pollutants can also vary by season due to differences in ventilation and activities between summer and winter. Therefore, assessing population exposure is very difficult.

\section{INDOOR AIR POLLUTION AND RESPIRATORY HEALTH IN THE URBAN ENVIRONMENT}

The main respiratory health effects of common indoor pollutants are summarised in figure 2.

\section{Biological pollutants}

The mostly studied respiratory effects of biological pollutants in the indoor environment are those of allergens. It has been estimated that more than half of asthma cases in the USA can be attributed to allergic sensitisation [36]. Numerous studies have found associations between exposure to indoor allergens and respiratory health, especially in the case of HDM [37, 38]. Some suggested implication of allergens in asthma development $[39,40]$. We will not detail these results in this section as several recent reviews have discussed this subject $[40,41]$. However, we would like to underline recent results, which suggest a nonlinear relationship between exposure to allergens and allergic diseases $[42,43]$ : high exposure to HDM allergens might be protective against the risks of asthma and allergic sensitisation. This has been suggested by the "high-dose tolerance" hypothesis put forward for exposure to the cat allergen [44]. Nevertheless, whether this hypothesis can be applied to other aeroallergens is not clear and still controversial [45].
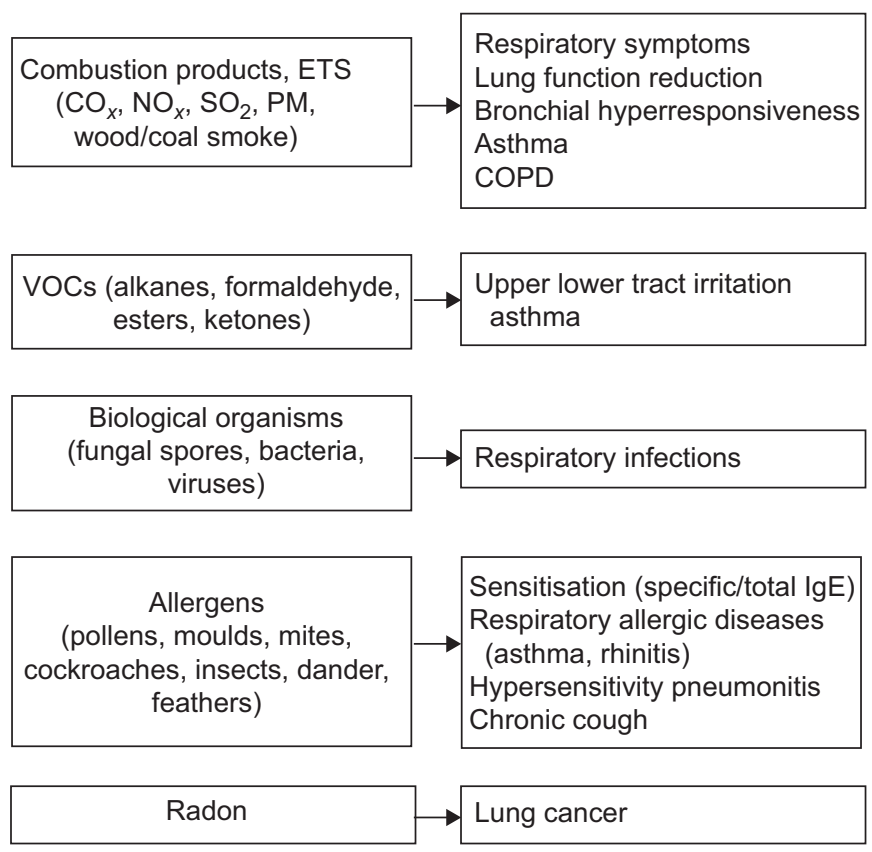

FIGURE 2. Main respiratory health effects of common indoor pollutants. ETS environmental tobacco smoke; $\mathrm{CO}_{x}$ : carbon oxides; $\mathrm{NO}_{x}$ : nitrogen oxides; $\mathrm{PM}$ : particulate matter; COPD: chronic obstructive pulmonary disease; VOC: volatile organic compounds; Ig: immunoglobulin.

Two other pollutants related to microbial exposure have been assessed in the indoor environment and associated with respiratory diseases: moulds and endotoxins.

\section{Moulds}

The epidemiological evidence for a relationship between respiratory health and exposure to indoor moulds is summarised in table S1.

The WHO has recently indicated that there is sufficient evidence to conclude that a relationship exists between exposure to indoor dampness and eight outcomes including asthma exacerbation/development and wheezing [7]. MENDELL et al. [46], using epidemiological studies and meta-analyses, showed that indoor dampness or mould are associated consistently with increased asthma development and exacerbation, current and ever diagnosis of asthma, dyspnoea, wheeze, cough, respiratory infections, bronchitis, allergic rhinitis, eczema, and upper respiratory tract symptoms in both allergic and nonallergic individuals. However, studies included in this analysis were mainly based on inhabitants' or technicians' report of dampness or moulds. Reliability of such assessment methods have been questioned. In fact, only weak associations have been found between visible signs of mould and objective assessment, such as spore counts [47-49], which could be due to underestimation of exposure in the case of hidden moulds. This was recently confirmed by MENDELL et al. [46] in their review of the impact of mould on respiratory health, in which suggestive evidence was available for only a few specifically measured microbiological factors and was in part equivocal, suggesting both adverse and protective associations with health.

Epidemiological studies based on objective assessment of mould exposure have mainly measured the number of fungal 
colonies in dust samples. Positive associations were found between the number of fungal colonies and the risk of allergic sensitisation [50-52], asthma [50, 52], wheezing [53, 54] or cough [53], but several results were not statistically significant [51-56]. The assessment of moulds through fungal colonies in dust samples presents several drawbacks: poor reproducibility, bias towards certain species, and nondetection of dead moulds or mould components. Thereafter, other methods have been developed in order to evaluate indoor exposure to moulds. They are based on objective measurements of mould markers such as ergosterol [52, 55] or extracellular polysaccharides [57]. The results are conflicting. Whereas increased risks of wheezing and allergic sensitisation to moulds were observed in relation to high ergosterol exposure in an Australian cohort [52, 55], negative associations were found in other studies. More recently, some epidemiological studies evaluated mould exposure based on $\beta$ glucans, a component of the fungal cell wall, or fungal products such as microbial volatile organic compounds (MVOCs) or mycotoxins, because of their pathogenic potency. However, the results by using such approach are still scarce and not conclusive. Some associations have been observed between $\beta(1 \rightarrow 3)$-glucan concentration and signs of airway inflammation, such as peak expiratory flow rate variability in children [58]. Other studies did not find significant results $[57,59]$. Only one case-control study in children found higher concentrations of this marker in the dwellings of subjects with asthma-like symptoms compared with the concentration found in controls' homes [58]. It is important to point out that adjusted associations were not assessed in that latter study. MVOCs have been assessed in only three epidemiological studies [33, 60, 61]. Two investigations have dealt with MVOC concentration in classrooms, and found a significant relation between it and the risks of wheezing, asthma and nocturnal breathlessness [33, 60]. More recently, positive associations were observed between a fungal index assessed with MVOCs and current asthma (8.6\%) and chronic bronchitis-like symptoms $(8.4 \%)$ in the inhabitants of the OQAI representative sample of the 24 million dwellings of metropolitan France $(n=567)$, especially in rural areas (OR 2.95 (95\% CI 1.10-7.95) and OR 3.35 (95\% CI 1.33-8.48), respectively). With regard to respiratory effects associated with fungal contamination, the role played by MVOCs is still controversial, because of their low specificity towards fungi and their very low concentrations in indoor air [62].

Although most studies focused on adverse respiratory effects of moulds, inverse associations were also observed between mould exposure and the risk of allergic/respiratory symptoms in young children [33, 57, 63]. The PIAMA (Prevention and Incidence of Asthma and Mite Allergy) study suggested a protective effect of early exposure to mould on asthma [57]. Indoor concentrations of $\beta$-glucan have also been negatively related to the risk of recurrent wheezing in a cohort of 574 children [63]. Moulds might therefore be involved in the protection conferred by microorganisms as suggested by the hygiene hypothesis, according to which, infections and unhygienic contacts may confer protection from the development of allergic illnesses (see later). Based on this hypothesis, the possible role of environmental exposure to microbial compounds and their effect on adaptive immunity have been explored.

Results of epidemiological studies, associated with clinical and toxicological studies, give good evidence of the effect of mould exposure on respiratory health. However, further studies are necessary to understand better the involvement of these various components on mould-related respiratory effects. Several mechanisms have been suggested to explain the associations between exposure to moulds and allergic and respiratory symptoms found in many studies. It has first been suggested that these microorganisms could induce an allergic response, through the production of immunoglobulin (Ig)E in response to mould allergens. Allergic sensitisation to moulds, and particularly to Alternaria alternata, has indeed been associated with asthma development and severity [64-67]. However, significant associations have also been found between exposure to moulds and respiratory symptoms among nonatopic subjects [68, 69]. A longitudinal study, including 622 children, has observed an increased risk of doctor-diagnosed asthma among nonatopic children, whereas no association was found among atopic ones [69]. At the same time, it has been suggested that some mould compounds might have respiratory effects through nonallergic pathways. Experimental studies on animals have indeed found that $\beta$-glucans and MVOCs may lead to inflammation and irritation [70,71]. Moulds may also lead to toxic effects through the production of mycotoxins. As previously discussed, there is insufficient evidence to implicate these compounds in mouldrelated respiratory effects.

\section{Endotoxins}

The epidemiological evidence for a relationship between respiratory health and exposure to indoor endotoxins is summarised in table S2.

In animal models and human challenge studies, endotoxins can induce an airway inflammation [72, 73]. Findings from epidemiological studies are less consistent [74]. Whereas some reports suggest a protective effect of endotoxins on the development of allergies [57, 75-77], others found that the exposure to endotoxins constitutes a risk factor for respiratory symptoms [78-84], which might depend on the amount of exposure [85].

The first studies that evaluated the respiratory effects of endotoxin exposure in an urban environment observed positive associations with asthma and wheezing [78-84]. In a cohort of 1,884 German newborns, a two-fold increased risk of wheezing during the first 6 months of life was found in children exposed to high endotoxin concentrations (OR 2.37, 95\% CI 1.40-4.03) [78]. Such associations have been confirmed in other longitudinal studies $[79,80,84]$, as well as in case-control or crosssectional studies [81-83]. Moreover, exposure to endotoxins has been linked to asthma severity and morbidity $[86,87]$.

However, several population-based studies have shown a decreased risk of wheezing [76], asthma [57, 76] and atopy $[76,88]$ in children living in urban homes with high endotoxin concentrations. Such a protective effect has been observed previously in rural populations, especially in the case of allergic sensitisation and atopic wheezing $[75,89]$. Based on these results, endotoxins have been suggested as a model of the protective effects played by microbial exposure on allergic diseases [75], as described in the hygiene hypothesis. The hygiene hypothesis states that exposure to allergens in the environment early in life reduces the risk of developing allergies. This hypothesis was put forward in 1989 STRACHAN [90], who, by observing a lower incidence of allergy in children of large families with three or 
more older siblings, proposed the existence of an inverse relationship between infectious diseases and allergies in the early childhood: the higher the number of older siblings (and, thus, of expected circulating infections in a family) the lower the risk of suffering from an allergic condition. Infections due to microbial compounds might, during the maturation of the immune system, promote a T-helper cell (Th) type 1-like response and avoid the Th2-like response responsible for the allergic cascade [91, 92]. Nowadays, new data suggest that components other than microbial compounds, such as moulds, might explain the hygiene hypothesis and therefore put into question the protective effect of endotoxin $[93,94]$.

Overall, exposure to biological contaminants in the indoor environment seems to have adverse effects on allergic and respiratory diseases. However, epidemiological findings also suggest that these pollutants might protect from allergies by simulating immune responses [95]. In addition, there is insufficient evidence of a potential protective effect of microorganisms on respiratory health $[95,96]$. Several questions are still unanswered. It has been shown that endotoxin could not only modulate the immune system but also lead to or exacerbate asthma through inflammation [74]. Such observations suggest that these compounds might have protective or adverse effects according to atopic status. Indeed, epidemiological studies have found positive $[68,69,88]$ and negative $[57,76]$ associations either in atopic or nonatopic asthma phenotypes. Moreover, timing of exposure seems to be crucial in order to understand how these components could be implicated in asthma. Some studies suggest these compounds could have respiratory effects, especially during early life [97]. Lastly, several contaminants have been suggested to be responsible for this protection and further studies are needed to clarify the contribution of each of them.

\section{Chemical air pollutants}

More studies exist on the links between indoor chemical air pollutants and respiratory health. They have mainly focused on exposure to nitrogen dioxide, particulate matter, formaldehyde and, to a lesser extent, VOCs.

\section{Nitrogen dioxide}

The epidemiological evidence for a relationship between respiratory health and exposure to indoor nitrogen dioxide is summarised in table S3.

Results of longitudinal studies on asthmatic populations or subjects at risk of developing asthma are quite conclusive: an increase in nitrogen dioxide concentration was associated with increased reporting of respiratory symptoms, including wheezing, breathing difficulty, chest tightness, shortness of breath and cough [98-103]. However, data at the general population level are more controversial. Few studies have found significantly increased risks of respiratory symptoms and asthma in association with higher concentration of nitrogen dioxide at home or at school [104-106]. Moreover, whether chronic exposure to indoor nitrogen dioxide contributes to the development of respiratory illness is unclear. Two longitudinal studies including children found a positive association between long-term exposure to indoor nitrogen dioxide and the risk of lower respiratory symptoms [107, 108]. In a Japanese cohort, exposure to nitrogen dioxide was associated with an increased risk of doctordiagnosed asthma and bronchitis, but not with the incidence of these diseases [109]. Two birth cohort studies that followed 1,611 infants for $1 \mathrm{yr}$ and 1,205 for 18 months, and one cohort survey including 842 children enrolled at 9-10 yrs of age did not confirm these results [109-111]. Reasons of these conflicting results are unknown, but the difficulties in determining real exposure to indoor nitrogen dioxide could explain them in part. In homes, exposure can fluctuate depending mainly on the season of measurement in conjunction with the use of specific sources, as gas appliances. Therefore, assessment over 1 week could not be representative of nitrogen dioxide exposure and, in particular, of peak concentrations during cooking or heating activities. Evidence of an association between exposure to indoor combustion, such as gas appliances, and asthma development and severity exists [112]. In a randomised controlled trial, the replacement of unflued gas heaters with flued gas or electric heaters showed a decrease in nitrogen dioxide concentration (15.5 versus $47.0 \mathrm{ppb}, \mathrm{p}<0.0001$ ) and a significantly reduced risk of breathing difficulty during the day and the night, chest tightness during the day and daytime asthma attacks in the intervention group [113]. Finally, inconsistencies among studies may also be due to modification by other pollutants or higher susceptibility in some subgroups, such as female children [109].

\section{Particulate matter}

The epidemiological evidence for a relationship between respiratory health and exposure to indoor particles is summarised in table S4.

In relation to particle size and chemical composition, particulate matter can have different adverse respiratory health effects depending on its deposition in the respiratory tract and the ability of the respiratory tree to remove it. Particles $>10 \mu \mathrm{m}$ are usually removed at the upper airways, PM10 (inhalable particles) tend to deposit in the nasal, pharyngeal and laryngeal regions of the respiratory systems, whereas PM2.5 (respirable particles) tend to deposit in the tracheobronchial region and alveoli. Recently, concern has grown about health effects of ultrafine particulates, defined as particulate matter $<100 \mathrm{~nm}$ in diameter.

Abundant literature suggests an effect of outdoor concentrations of particles on respiratory diseases [114]. Indoors, most studies have focused on particulate matter sources such as ETS [115] or cooking and heating appliances, but few on measured particulate matter concentration. A review of the effect of second-hand smoke concluded that there was evidence of a causal relationship between ETS and asthma severity and development, especially in children [116].

More than half of the epidemiological studies using objective measurements of particulate matter have been published during the last 4 yrs. Significant associations were mainly observed among symptomatic subjects. In this population, indoor particulate matter concentration has been related to a decrease in lung function, in particular among children with asthma [117-120] and, to a lesser extent, to an increased risk of asthmatic and bronchitis-like symptoms [121, 122]. In a cohort of 150 asthmatic children, PM2.5 and PM2.5-10 concentrations, assessed three times every 3 months, were positively associated with the incidence rate of several respiratory symptoms, including cough, asthma symptoms and wheezing [121]. A pilot study on IAQ in a sample of schools in five European countries found that nasal 
patency was significantly lower in schoolchildren exposed to PM10 concentrations $>50 \mu \mathrm{g} \cdot \mathrm{m}^{-3}$ than in those exposed to concentrations $<50 \mu \mathrm{g} \cdot \mathrm{m}^{-3}$ [34]. An increased risk of past-year asthma was found in 401 classrooms with high levels of particulate matter (OR 1.21, 95\% CI 1.05-1.39) [35].

Results in dwellings are less conclusive. Only one longitudinal study [122] and one cross-sectional study [123] found significant associations with the risk of respiratory symptoms. More work is needed to clarify whether or not there is an association between indoor exposure to particles and asthma or bronchitis severity in the general population as well as with respiratory diseases development.

\section{Formaldehyde and VOCs}

Sources of formaldehyde and VOCs at home, such as indoor residential materials and coatings as well as renovation or cleaning activities, have been associated with respiratory effects $[3,124]$. However, health studies using objective measurement of VOCs are scarce and have mainly been conducted within paediatric populations.

Formaldehyde is one of the mostly studied pollutants in indoor air (table S5). Several cross-sectional studies showed an increased risk of asthma with high exposure to indoor formaldehyde [3, 125-127], whereas some did not find any significant result [33, $83,128]$. The first longitudinal study on the respiratory effects of indoor formaldehyde found a significant positive association between formaldehyde concentration and incidence of asthma diagnosis (OR 1.7, 95\% CI 1.1-2.6, for each formaldehyde increment of $10 \mu \mathrm{g} \cdot \mathrm{m}^{-3}$ ), but only among non-atopic children [69]. In a recent meta-analysis, McGwIN et al. [129] calculated a $17 \%$ increase in the risk of asthma (OR 1.17, 95\% CI 1.01-1.36) for each $10 \mu \mathrm{g} \cdot \mathrm{m}^{-3}$ unit increase in formaldehyde concentration. Lastly, there is some convincing evidence of an effect of formaldehyde in asthma morbidity, such as respiratory symptoms or lung function [35, 106, 125, 128, 130-132].

Other indoor VOCs have been studied in relation to respiratory health (table S6). Among the seven epidemiological studies having dealt with this topic, three highlighted significant associations between indoor concentration of VOCs and asthma or asthma-like symptoms [127, 131, 133]. This was confirmed by a survey using personal assessment of VOC exposure [134], showing an increased risk of doctor-diagnosed asthma among those exposed to VOCs and, in particular, to aromatic compounds (OR 1.63, 95\% CI 1.17-2.27). While two studies suggest that exposure to VOC in utero could have an impact on immune status of newborns [135, 136], no epidemiological study using objective measurements reports significant associations between exposure to formaldehyde and allergic sensitisation.

Overall, despite a still scarce literature, evidence of an association between chemical pollutants from the indoor environment and respiratory health of the residents is increasing. A large number of studies evaluated the relations between respiratory health and nitrogen dioxide exposure, whereas relatively little research has focused on particles, formaldehyde or VOCs. For these pollutants, data on asthma exacerbation are quite consistent but other studies are needed to suggest their implication on asthma morbidity or development. Moreover, analyses of specific VOCs and not only on total VOCs could enable us to identify some adverse pollutants.

\section{Emerging air pollutants}

Phthalates and POPs have scarcely been considered in connection to respiratory health because the greatest concern about these chemical materials is over effects on reproduction and human development. However, recent work supports the hypothesis of phthalates as a potential additional risk factor for respiratory health. Airborne phthalate esters are endocrine disruptors that may act as modulators of the immune system and induce an allergic response. One of the main sources for phthalate esters indoors is the plasticised polyvinyl chloride (PVC) materials that are used in floor and wall covering materials, shower curtains, adhesives, synthetic leather, toys, cosmetics, and many other consumer products. The phthalate concentration in indoor air is usually lower than that in dust. Human exposure to phthalates has been studied mainly by monitoring concentrations of metabolites in body fluids. There is evidence that people are exposed to a variety of phthalates and that children often are more exposed than adults. Although the greatest concern about phthalates is regarding reproduction and human development, a relationship has been shown between indoor exposure to phthalates, within the range of what is normally found in dwellings, and allergic symptoms in children [137]. The effects of phthalates in indoor air might have been confounded by the presence of other PVC surface materials, moulds or dampness. Dampness enhances both microbial growth and degradation of PVC materials, both of which are potential determinants of asthma. Large-scale epidemiological studies in different populations and housing conditions are needed to investigate respiratory effects of indoor exposure to phthalates. Recently, a USA study showed a significantly elevated risk of asthma (rate ratio (RR) 1.09), infectious respiratory disease (RR 1.15) and COPD (RR 1.19) in individuals living in a zip code with a POP waste site [138]. So far, only experimental or occupational data exist for BFRs, such himic anhydride powder. These observations are consistent with the hypothesis that exposure to emerging substances may contribute to respiratory diseases.

\section{Potential mechanisms}

Several mechanisms have been suggested to explain the observed associations, but full comprehension is lacking and certainly has to be modulated according to the type of air pollutant. Two mechanisms have been privileged. One implicates oxidative stress and the production of reactive oxygen species leading to inflammation [139] according to a dosedependent response to air pollutant exposure. At high exposure, oxidative stress leads to the activation of additional intracellular signalling cascades and then increase expression of proinflammatory cytokines (such as tumour necrosis factor- $\alpha$ and interleukins- 8 and -6). These products are produced locally in target tissues as well as systemically and they lead to widespread pro-inflammatory effects remotely from the site of the damage. The other mechanism suggests interactions between allergen and pollutants [140]. Some pollutants, in particular, diesel exhaust particles (DEPs), nitrogen dioxide, ozone and sulfur dioxide, could enhance airway responses to inhaled allergens. It has been shown that DEP, in synergy with allergens, could enhance allergen-specific IgE production by initiating a Th2 cytokine environment in the human upper respiratory mucosa. Recently, it has been shown that VOCs and formaldehyde could also have such interaction effects $[133,140]$. Only a few studies have evaluated the relationship between exposure to indoor 
pollution and asthma according to different phenotypes. Such results could bring novel elements to better understand the adverse effect of indoor pollutants and associated mechanisms.

\section{INDOOR AIR POLLUTION AND RESPIRATORY HEALTH IN THE RURAL ENVIRONMENT}

Most of the epidemiological studies evaluating the associations between indoor air pollution and respiratory health in industrialised countries have focused on urban areas. Only a few studies have been conducted in rural areas where air pollution differs in intensity and sources from the ones in urban areas. Most researches conducted in rural areas of developing and emerging countries studied the impact of the use of biomass fuels. In the European Respiratory Journal Series on Air Pollution, the first series article discusses indoor pollution in low and medium countries. Studies on respiratory effects of indoor air pollution in rural areas of industrialised countries are of particular interest as individuals living since birth in these zones suffer less from allergies but are more affected by COPD and this in spite of the fact that they smoke less. Indoor air pollution of the farming environment, characterised by an excess of bio-contaminants, might partly explain such effects. We summarise in this section the effects of air pollution found in the rural setting as its comprehension could lead to a better understanding of respiratory and allergic diseases.

\section{In children}

The epidemiological evidence for a relationship between respiratory health and exposure to indoor pollutants in rural areas in children is summarised in table S7.

The protective effect of farming environment against allergies has been discussed extensively [141, 142]. Several studies have observed reduced prevalence of allergic sensitisation and, to a lesser extent, of asthma in children exposed to farms, compared with rural peers $[143,144]$. Based on the hygiene hypothesis, it has been suggested that exposure to high concentrations of biological compounds in this environment could explain the observed protective effect $[75,93,145]$.

Initially, endotoxin was designated as the "ideal" candidate to explain such a protective effect. Higher indoor concentrations were found in farming environments compared with those assessed in homes of the surrounded rural areas [146]. Exposure to animals, especially farm animals, has been suggested to explain such differences [147]. However, moulds have also been suggested as potential candidates [93, 145]. Even after adjustment for endotoxin concentration, a negative association was found between exposure to moulds, assessed through muramic acid concentration, and the risk of wheezing [93]. Based on the recent observation of very high concentrations of allergens on farms [148], the hypothesis of tolerance induction by antigen exposure in early life [44] has been raised to explain the protective effect of farming environment. However, the only study that objectively assessed allergen concentrations at home did not find any significant association with allergic sensitisation [42]. As a consequence, because of a lack of data, the hypothesis of immune tolerance induction is controversial, and further studies are needed in order to replicate previous results and to better understand how biological exposure might interact with the immune system [149].
To summarise, indoor air biological pollution seems to be an important factor to explain the protection afforded by the farming environment in the case of allergic diseases in early life. Results using objective assessment of indoor bio-contaminants in this environment enable us to highlight several candidates that could be responsible for this effect during the first years of life, a period that has been suggested to be crucial in the protective effect of the farming environment [141]. In the framework of the Prevention of Allergy-Risk Factors for Sensitization Related to Farming and Anthroposophic Lifestyle (PARSIFAL) study including five European countries, dust samples from mothers' mattresses were collected just after childbirth [150]. Only weak associations were found between endotoxins and extracellular polysaccharides concentrations and pro-inflammatory cytokines concentrations in cord blood. Moreover, exposure to pollution has been assessed in homes and not on farms, whereas high concentrations can be found in this environment due to farming activities. Therefore, more studies are needed to better understand which specific aspect of this environment, especially associated with indoor pollution, might explain the low prevalence of allergies among farm children. In PARSIFAL and the Genetic and Environmental Causes of Asthma in the European Community (GABRIEL) Advanced study, children who lived on farms had lower prevalences of asthma and atopy, and were exposed to a greater variety of environmental nonpathogenic microorganisms than the children in the reference group [151]. The diversity of microbial exposure was inversely related to the risk of asthma (OR for PARSIFAL 0.62, 95\% CI 0.44-0.89; OR for GABRIEL Advanced $0.86,95 \%$ CI $0.75-0.99)$. In addition, the presence of certain more circumscribed exposures was also inversely related to the risk of asthma; this included exposure to species in the fungal taxon Eurotium spp. (adjusted OR 0.37, 95\% CI 0.18-0.76) and to a variety of bacterial species, including Listeria monocytogenes, Bacillus spp., Corynebacterium species and others (adjusted OR 0.57, 95\% CI 0.38-0.86). These results illustrate the complexity underlying the development of asthma and allergies.

\section{In adults}

The epidemiological evidence for a relationship between respiratory health and exposure to indoor pollutants in rural areas in adults is summarised in table S8.

Exposure to farming environment has been associated with an increase in respiratory symptoms [152, 153]. During agricultural work, farmers and farm workers are exposed to a wide variety of air pollutants such as organic dusts, toxic gases, endotoxin, microorganisms and chemicals, including herbicides and pesticides [154-156]. These pollutants are some of the most common occupational and environmental health hazards encountered by the individuals working on farms. Specific tasks (cow-shed work, cattle foddering, cereal mixing for animals and cow-shed cleaning) have been associated with an increased risk of some respiratory symptoms, including chronic cough, dyspnoea and chronic phlegm [157, 158]. This increased risk of respiratory symptoms was confirmed by studies that objectively assessed pollution exposure. Exposure to dust and endotoxin was significantly associated with a decline in lung function [159-161], and the risk of COPD-like symptoms [162, 163], chronic bronchitis and COPD [164, 165]. Only two studies reported similar associations with mould 
exposure $[164,166]$. Results on asthma are few but suggest different effects of pollution according to atopic status. In 2004, EDUARD et al. [167], in a population of 1,614 animal farmers, found that exposure to fungal spores was associated with an increased risk of nonatopic asthma and a decreased risk of atopic asthma. A recent study including 427 farmers found that high endotoxin exposure is a risk factor for bronchial hyperresponsiveness and wheezing, whereas, at the same time, it is related to a reduced risk of atopy and $\operatorname{IgE}$ to grass pollen in adults [168]. The observation that farm environment is associated with either an increased or a decreased risk of respiratory diseases has been named the "agricultural asthma paradox" [169]: early farm exposures, especially those in the first year of life, reduce the incidence of atopy and atopic asthma, while exposures later in life increase the risk of nonatopic asthma.

Overall, epidemiological studies focusing on indoor exposure of farmers suggest that the farming environment might be responsible for both adverse and protective respiratory effects. However, as for the child population, the responsible compounds have not completely been identified. Several pollutants, including biological contaminants and PM2.5, could be implicated. Evaluation of exposure in this environment is very difficult. First, pollutant concentrations depend on the type of farm, specific task realized during the work and agricultural practices (use of machinery, of specific animal food, etc.). Therefore, long sampling periods during a wide variety of tasks and on different farms are necessary to obtain a thorough assessment of farmers' exposure and better understand the responsibility of such exposure on respiratory health. Moreover, high correlations between biological compounds lead to multicollinearity, and make it more difficult to study the independent effects of specific biological agents.

In rural areas, specific habits can lead to different pollutants or concentrations than in urban areas. Therefore, particular effects associated with indoor pollution have been suggested. In farming environments, the study of indoor pollution and its relationship with respiratory health might enable researchers to better understand the mechanism associated with such effects.

\section{CONCLUSION}

Growing interest in IAQ and related health effects have led to the publication of important results, especially in the last $10 \mathrm{yrs}$. Diversity of indoor pollutants and inhabitants habits can lead to a wide variety of IAQ profiles throughout the world. Results of epidemiological studies suggest that respiratory effects are associated with exposure to air pollution. Even at a low concentration, indoor chronic exposure might be responsible for important adverse effects on health. Studies focusing on the association between dwelling characteristics or occupants' activities reinforce the hypothesis of implications of IAQ in respiratory health. However, for some pollutants, more results are necessary in order to have sufficient information about associations between exposure and respiratory health. Data on birth cohorts are necessary to evaluate potential effects of IAQ on respiratory disease development. Several mechanisms have been suggested to explain the relationship between exposure to air pollution and adverse respiratory effects, based on both allergic and nonallergic pathways. For some pollutants, both types of mechanisms could act. Specific exposure, mainly biological, seems to have contradictory effects according to pollutants, time and duration. In the rural environment, such a paradox has often been observed. Therefore, studies are needed to better understand the mechanisms associated with the exposure to indoor air pollutants and to evaluate the potential implication of indoor pollution on respiratory disease development. Moreover, data on the rural environment are needed, as this environment seems to be particularly interesting for evaluating the impact of indoor air pollution on allergic and respiratory diseases.

Such information is essential to evaluate the risk associated with indoor pollution and establish public policies on IAQ. SCHER indicated, in its opinion on risk assessment on indoor air quality [5], that "indoor air constitutes a complex case for risk assessment and management due to a wide variety of pollutants, exposure levels, different possible health outcomes, differences in sensitivity of the population, cultural habits, way of living, building stock and climate across Europe." However, as concluded by SCHER, the database for indoor air risk assessment is in general limited and more data on exposure, in quantitative terms, are required. Therefore, the development of exposure assessment and its use in epidemiological studies is needed to better evaluate the risk associated with indoor pollution and protect the population.

\section{STATEMENT OF INTEREST}

None declared.

\section{REFERENCES}

1 Cohen AJ, Ross Anderson H, Ostro B, et al. The global burden of disease due to outdoor air pollution. J Toxicol Environ Health A 2005; 68: 1301-1307.

2 Maio S, Cerrai S, Simoni M, et al. Environmental risk factors: indoor and outdoor pollution. In: Pawankar R, Canonica GW, Holgate ST, eds. WAO White Book on Allergy. Milwaukee, World Allergy Organization, 2011; pp. 84-90.

3 Viegi G, Simoni M, Scognamiglio A, et al. Indoor air pollution and airway disease. Int J Tuberc Lung Dis 2004; 8: 1401-1415.

4 Richardson G, Eick S, Jones R. How is the indoor environment related to asthma? J Adv Nurs 2005; 52: 328-339.

5 Scientific Committee on Health and Environmental Risks. Opinion on risk assessment on indoor air quality. Brussels, European Commission, 2007.

6 Smith BJ, Mehta S, Maeusezahl-Feuz M. Indoor air pollution from household use of solid fuels: comparative quantification of health risks. In: Ezzati MLA, Rodgers A, Murray CJL, eds. Global and regional burden of disease attributable to selected major risk factors. Geneva, World Health Organization, 2004; pp. 1435-1493.

7 World Health Organization. WHO guidelines for indoor air quality: dampness and mould. Copenhagen, World Health Organization, 2009.

8 Baena-Cagnani CE, Gomez RM, Baena-Cagnani R, et al. Impact of environmental tobacco smoke and active tobacco smoking on the development and outcomes of asthma and rhinitis. Curr Opin Allergy Clin Immunol 2009; 9: 136-140.

9 Dassonville C, Demattei C, Laurent AM, et al. Assessment and predictor determination of indoor aldehyde levels in Paris newborn babies' homes. Indoor Air 2009; 19: 314-323.

10 Gilbert NL, Gauvin D, Guay M, et al. Housing characteristics and indoor concentrations of nitrogen dioxide and formaldehyde in Quebec City, Canada. Environ Res 2006; 102: 1-8.

11 Salo PM, Arbes SJ Jr. , Crockett PW, et al. Exposure to multiple indoor allergens in US homes and its relationship to asthma. J Allergy Clin Immunol 2008; 121: 678-684. 
12 Kirchner S, Arenes JF, Cochet C, et al. Campagne nationale logements: etat de la qualité de l'air dans les logements français rapport final [National survey: indoor air quality in French dwellings - final report]. Paris, Observatory on Indoor Air Quality, 2006.

13 Zock JP, Heinrich J, Jarvis D, et al. Distribution and determinants of house dust mite allergens in Europe: the European Community Respiratory Health Survey II. J Allergy Clin Immunol 2006; 118: 682-690.

14 Heinrich J, Bedada GB, Zock JP, et al. Cat allergen level: its determinants and relationship to specific $\operatorname{IgE}$ to cat across European centers. J Allergy Clin Immunol 2006; 118: 674-681.

15 Thorne PS, Cohn RD, Mav D, et al. Predictors of endotoxin levels in US housing. Environ Health Perspect 2009; 117: 763-771.

16 Chen CM, Thiering E, Doekes G, et al. Geographical variation and the determinants of domestic endotoxin levels in mattress dust in Europe. Indoor Air 2012; 22: 24-32.

17 Institute of Medicine. Damp Indoor Spaces and Health. Washington, Institute of Medicine, 2004.

18 Gunnbjornsdottir MI, Franklin KA, Norback D, et al. Prevalence and incidence of respiratory symptoms in relation to indoor dampness: the RHINE study. Thorax 2006; 61: 221-225.

19 Mudarri D, Fisk WJ. Public health and economic impact of dampness and mold. Indoor Air 2007; 17: 226-235.

20 Moularat S, Derbez M, Kirchner S, et al. Détermination de la contamination fongique des logements français par un indice chimique [Determination of fungal contamination in French dwellings using a chemical marker]. Pollution Atmosphérique 2008; 197: 37-44.

21 Moularat S, Hulin M, Robine E, et al. Airborne fungal volatile organic compounds in rural and urban dwellings: detection of mould contamination in 94 homes determined by visual inspection and airborne fungal volatile organic compounds method. Sci Total Environ 2011; 409: 2005-2009.

22 Gotschi T, Oglesby L, Mathys P, et al. Comparison of black smoke and PM2.5 levels in indoor and outdoor environments of four European cities. Environ Sci Technol 2002; 36: 1191-1197.

23 Jurvelin J, Edwards R, Saarela K, et al. Evaluation of VOC measurements in the EXPOLIS study. Air pollution exposure distributions within adult urban populations in Europe. J Environ Monit 2001; 3: 159-165.

24 Rotko T, Oglesby L, Kunzli N, et al. Population sampling in European air pollution exposure study, EXPOLIS: comparisons between the cities and representativeness of the samples. J Expo Anal Environ Epidemiol 2000; 10: 355-364.

25 Seifert B, Becker K, Hoffmann K, et al. The German Environmental Survey 1990/1992 (GerES II): a representative population study. J Expo Anal Environ Epidemiol 2000; 10: 103-114.

26 Seifert B, Becker K, Helm D, et al. The German Environmental Survey 1990/1992 (GerES II): reference concentrations of selected environmental pollutants in blood, urine, hair, house dust, drinking water and indoor air. I Expo Anal Environ Epidemiol 2000; 10: 552-565.

27 Kolossa-Gehring M, Becker K, Conrad A, et al. German Environmental Survey for Children (GerES IV) - first results. Int J Hyg Environ Health 2007; 210: 535-540.

28 MRC Institute for Environment and Health. Indoor air quality in the home: nitrogen dioxide, formaldehyde, volatile organic compounds, house dust mites, fungi and bacteria. Leicester, University of Leicester, 1996.

29 Billionnet C, Gay E, Kirchner S, et al. Quantitative assessments of indoor air pollution and respiratory health in a population-based sample of French dwellings. Environ Res 2011; 111: 425-434.

30 Pellizzari E, Lioy P, Quackenboss J, et al. Population-based exposure measurements in EPA region 5; a phase I field study in support of the National Human Exposure Assessment Survey. J Expo Anal Environ Epidemiol 1995; 5: 327-358.
31 Logue JM, McKone TE, Sherman MH, et al. Hazard assessment of chemical air contaminants measured in residences. Indoor Air 2011; 21: 92-109.

32 Girman JR, Hdwen GE, Burton LE, et al. Individual volatile organic compound prevalence and concentration in 56 buildings of the building survey and evaluation (BASE) study. In: Raw G, ed. Proceedings of the Eighth International Conference on Indoor Air Quality and Climate. London, Construction Research Communications Ltd., 1999; pp. 460-465.

33 Kim JL, Elfman L, Mi Y, et al. Indoor molds, bacteria, microbial volatile organic compounds and plasticizers in schools-associations with asthma and respiratory symptoms in pupils. Indoor Air 2007; 17: 153-163.

34 Simoni M, Annesi-Maesano I, Sigsgaard T, et al. School air quality related to dry cough, rhinitis and nasal patency in children. Eur Respir J 2010; 35: 742-749.

35 Annesi-Maesano I, Hulin M, Lavaud F, et al. Poor air quality in classrooms related to asthma and rhinitis in primary schoolchildren of the French 6 Cities Study. Thorax 2012; 67: 682-688.

36 Arbes SJ Jr., Gergen PJ, Vaughn B, et al. Asthma cases attributable to atopy: results from the Third National Health and Nutrition Examination Survey. J Allergy Clin Immunol 2007; 120: 1139-1145.

37 Korsgaard J. House-dust mites and asthma. A review on housedust mites as a domestic risk factor for mite asthma. Allergy 1998; 53: 77-83.

38 van der Heide S, Dubois AE, Kauffman HF, et al. Allergy to mites: relation to lung function and airway hyperresponsiveness. Allergy 1998; 53: 104-107.

39 Afshari A, Matson U, Ekberg LE. Characterization of indoor sources of fine and ultrafine particles: a study conducted in a full-scale chamber. Indoor Air 2005; 15: 141-150.

40 Gaffin JM, Phipatanakul W. The role of indoor allergens in the development of asthma. Curr Opin Allergy Clin Immunol 2009; 9: 128-135.

41 Salo PM, Sever ML, Zeldin DC. Indoor allergens in school and day care environments. J Allergy Clin Immunol 2009; 124: 185-192.

42 Schram-Bijkerk D, Doekes G, Boeve M, et al. Nonlinear relations between house dust mite allergen levels and mite sensitization in farm and nonfarm children. Allergy 2006; 61: 640-647.

43 Tovey ER, Almqvist C, Li Q, et al. Nonlinear relationship of mite allergen exposure to mite sensitization and asthma in a birth cohort. J Allergy Clin Immunol 2008; 122: 114-118.

44 Hesselmar B, Aberg N, Aberg B, et al. Does early exposure to cat or dog protect against later allergy development? Clin Exp Allergy 1999; 29: 611-617.

45 Brussee JE, Smit HA, van Strien RT, et al. Allergen exposure in infancy and the development of sensitization, wheeze, and asthma at 4 years. J Allergy Clin Immunol 2005; 115: 946-952.

46 Mendell MJ, Mirer AG, Cheung K, et al. Respiratory and allergic health effects of dampness, mold, and dampness-related agents: a review of the epidemiologic evidence. Environ Health Perspect 2011; 119: 748-756.

47 Dales RE, Miller D, McMullen E. Indoor air quality and health: validity and determinants of reported home dampness and moulds. Int J Epidemiol 1997; 26: 120-125.

48 Platt SD, Martin CJ, Hunt SM, et al. Damp housing, mould growth, and symptomatic health state. BMJ 1989; 298: 1673-1678.

49 Verhoeff AP, van Wijnen JH, van Reenen-Hoekstra ES, et al. Fungal propagules in house dust. II. Relation with residential characteristics and respiratory symptoms. Allergy 1994; 49: 540-547.

50 Garrett MH, Rayment PR, Hooper MA, et al. Indoor airborne fungal spores, house dampness and associations with environmental factors and respiratory health in children. Clin Exp Allergy 1998; 28: 459-467.

51 Jacob B, Ritz B, Gehring U, et al. Indoor exposure to molds and allergic sensitization. Environ Health Perspect 2002; 110: 647-653. 
52 Matheson MC, Abramson MJ, Dharmage SC, et al. Changes in indoor allergen and fungal levels predict changes in asthma activity among young adults. Clin Exp Allergy 2005; 35: 907-913.

53 Gent JF, Ren P, Belanger K, et al. Levels of household mold associated with respiratory symptoms in the first year of life in a cohort at risk for asthma. Environ Health Perspect 2002; 110: A781-A786.

54 Belanger K, Beckett $W$, Triche E, et al. Symptoms of wheeze and persistent cough in the first year of life: associations with indoor allergens, air contaminants, and maternal history of asthma. Am J Epidemiol 2003; 158: 195-202.

55 Dharmage S, Bailey M, Raven J, et al. Current indoor allergen levels of fungi and cats, but not house dust mites, influence allergy and asthma in adults with high dust mite exposure. Am J Respir Crit Care Med 2001; 164: 65-71.

56 Jovanovic S, Felder-Kennel A, Gabrio T, et al. Indoor fungi levels in homes of children with and without allergy history. Int J Hyg Environ Health 2004; 207: 369-378.

57 Douwes J, van Strien R, Doekes G, et al. Does early indoor microbial exposure reduce the risk of asthma? The Prevention and Incidence of Asthma and Mite Allergy birth cohort study. J Allergy Clin Immunol 2006; 117: 1067-1073.

58 Douwes J, Zuidhof A, Doekes G, et al. $(1 \rightarrow 3)-\beta$-D-glucan and endotoxin in house dust and peak flow variability in children. Am J Respir Crit Care Med 2000; 162: 1348-1354.

59 Bertelsen RJ, Carlsen KC, Carlsen $\mathrm{KH}$, et al. Childhood asthma and early life exposure to indoor allergens, endotoxin and $\beta(1,3)$ glucans. Clin Exp Allergy 2010; 40: 307-316.

60 Smedje G, Norback D, Wessen B, et al. Asthma among school employees in relation to the school environment. In: Indoor Air '96: Proceedings of the 7th International Conference on Indoor Air Quality and Climate (July 21-26, 1996, Nagoya, Japan). Nagoya, International Society of Indoor Air Quality and Climate, 1996; pp. 611-616.

61 Hulin M, Moularat S, Kirchner S, et al. Positive associations between respiratory outcomes and fungal index in rural inhabitants of a representative sample of French dwellings. Int J Hyg Environ Health 2012; [Epub ahead of print DOI: 10.1016/ j.ijheh.2012.02.011].

62 Pasanen AL, Korpi A, Kasanen JP, et al. Critical aspects on the significance of microbial volatile metabolites as indoor air pollutants. Environ Int 1998; 24: 703-712.

63 Iossifova YY, Reponen T, Bernstein DI, et al. House dust (13)- $\beta$-D-glucan and wheezing in infants. Allergy 2007; 62: 504-513.

64 Bush RK, Prochnau JJ. Alternaria-induced asthma. J Allergy Clin Immunol 2004; 113: 227-234

65 Halonen M, Stern DA, Wright AL, et al. Alternaria as a major allergen for asthma in children raised in a desert environment. Am J Respir Crit Care Med 1997; 155: 1356-1361.

66 Salo PM, Arbes SJ Jr., Sever M, et al. Exposure to Alternaria alternata in US homes is associated with asthma symptoms. J Allergy Clin Immunol 2006; 118: 892-898.

67 Zureik M, Neukirch C, Leynaert B, et al. Sensitisation to airborne moulds and severity of asthma: cross sectional study from European Community respiratory health survey. BMJ 2002; 325 411-414.

68 Ronmark E, Perzanowski M, Platts-Mills T, et al. Incidence rates and risk factors for asthma among school children: a 2-year follow-up report from the obstructive lung disease in Northern Sweden (OLIN) studies. Respir Med 2002; 96: 1006-1013.

69 Smedje G, Norback D. Incidence of asthma diagnosis and selfreported allergy in relation to the school environment - a fouryear follow-up study in schoolchildren. Int J Tuberc Lung Dis 2001; 5: 1059-1066.

70 Bush RK, Portnoy JN, Saxon A, et al. The medical effects of mold exposure. J Allergy Clin Immunol 2006; 117: 326-333.
71 Douwes J. (1 $\rightarrow 3)$ - $\beta$-D-glucans and respiratory health: a review of the scientific evidence. Indoor Air 2005; 15: 160-169.

72 Pauwels RA, Kips JC, Peleman RA, et al. The effect of endotoxin inhalation on airway responsiveness and cellular influx in rats. Am Rev Respir Dis 1990; 141: 540-545.

73 Sandström T, Bjermer L, Rylander R. Lipopolysaccharide (LPS) inhalation in healthy subjects increases neutrophils, lymphocytes and fibronectin levels in bronchoalveolar lavage fluid. Eur Respir J 1992; 5: 992-996.

74 Douwes J, Pearce N, Heederik D. Does environmental endotoxin exposure prevent asthma? Thorax 2002; 57: 86-90.

75 Braun-Fahrlander C, Riedler J, Herz U, et al. Environmental exposure to endotoxin and its relation to asthma in school-age children. N Engl J Med 2002; 347: 869-877.

76 Gehring U, Strikwold M, Schram-Bijkerk D, et al. Asthma and allergic symptoms in relation to house dust endotoxin: Phase Two of the International Study on Asthma and Allergies in Childhood (ISAAC II). Clin Exp Allergy 2008; 38: 1911-1920.

77 Gereda JE, Leung DY, Thatayatikom A, et al. Relation between house-dust endotoxin exposure, type $1 \mathrm{~T}$-cell development, and allergen sensitisation in infants at high risk of asthma. Lancet 2000; 355: 1680-1683.

78 Gehring $\mathrm{U}$, Bolte $\mathrm{G}$, Borte $\mathrm{M}$, et al. Exposure to endotoxin decreases the risk of atopic eczema in infancy: a cohort study. J Allergy Clin Immunol 2001; 108: 847-854.

79 Litonjua AA, Milton DK, Celedon JC, et al. A longitudinal analysis of wheezing in young children: the independent effects of early life exposure to house dust endotoxin, allergens, and pets. J Allergy Clin Immunol 2002; 110: 736-742.

80 Bolte G, Bischof W, Borte M, et al. Early endotoxin exposure and atopy development in infants: results of a birth cohort study. Clin Exp Allergy 2003; 33: 770-776.

81 Tavernier GO, Fletcher GD, Francis HC, et al. Endotoxin exposure in asthmatic children and matched healthy controls. results of IPEADAM study. Indoor Air 2005; 15: Suppl. 10, 25-32.

82 Thorne PS, Kulhankova K, Yin M, et al. Endotoxin exposure is a risk factor for asthma: the national survey of endotoxin in United States housing. Am J Respir Crit Care Med 2005; 172: 1371-1377.

83 Tavernier G, Fletcher G, Gee I, et al. IPEADAM study: indoor endotoxin exposure, family status, and some housing characteristics in English children. I Allergy Clin Immunol 2006; 117: 656-662.

84 Perzanowski MS, Miller RL, Thorne PS, et al. Endotoxin in innercity homes: associations with wheeze and eczema in early childhood. J Allergy Clin Immunol 2006; 117: 1082-1089.

85 Niven R. The endotoxin paradigm: a note of caution. Clin Exp Allergy 2003; 33: 273-276.

86 Michel O, Ginanni R, Duchateau J, et al. Domestic endotoxin exposure and clinical severity of asthma. Clin Exp Allergy 1991; 21: $441-448$

87 Michel O, Kips J, Duchateau J, et al. Severity of asthma is related to endotoxin in house dust. Am J Respir Crit Care Med 1996; 154 1641-1646.

88 Celedon JC, Milton DK, Ramsey CD, et al. Exposure to dust mite allergen and endotoxin in early life and asthma and atopy in childhood. J Allergy Clin Immunol 2007; 120: 144-149.

89 Gehring U, Bischof W, Fahlbusch B, et al. House dust endotoxin and allergic sensitization in children. Am J Respir Crit Care Med 2002; 166: 939-944.

90 Strachan DP. Hay fever, hygiene, and household size. BMJ 1989; 299: 1259-1260.

91 Holt PG, Sly PD, Bjorksten B. Atopic versus infectious diseases in childhood: a question of balance? Pediatr Allergy Immunol 1997; 8 53-58.

92 Martinez FD, Holt PG. Role of microbial burden in aetiology of allergy and asthma. Lancet 1999; 354: Suppl. 2, SII12-SII15. 
93 van Strien RT, Engel R, Holst O, et al. Microbial exposure of rural school children, as assessed by levels of $\mathrm{N}$-acetyl-muramic acid in mattress dust, and its association with respiratory health. J Allergy Clin Immunol 2004; 113: 860-867.

94 Schram D, Doekes G, Boeve M, et al. Bacterial and fungal components in house dust of farm children, Rudolf Steiner school children and reference children - the PARSIFAL Study. Allergy 2005; 60: 611-618.

95 von Mutius E. Allergies, infections and the hygiene hypothesisthe epidemiological evidence. Immunobiology 2007; 212: 433-439.

96 Liu AH. Hygiene theory and allergy and asthma prevention. Paediatr Perinat Epidemiol 2007; 21: Suppl. 3, 2-7.

97 Simoni M, Lombardi E, Berti G, et al. Mould/dampness exposure at home is associated with respiratory disorders in Italian children and adolescents: the SIDRIA-2 Study. Occup Environ Med 2005; 62: 616-622.

98 Belanger K, Gent JF, Triche EW, et al. Association of indoor nitrogen dioxide exposure with respiratory symptoms in children with asthma. Am J Respir Crit Care Med 2006; 173: 297-303.

99 Kattan M, Gergen PJ, Eggleston P, et al. Health effects of indoor nitrogen dioxide and passive smoking on urban asthmatic children. J Allergy Clin Immunol 2007; 120: 618-624.

100 Nitschke M, Pilotto LS, Attewell RG, et al. A cohort study of indoor nitrogen dioxide and house dust mite exposure in asthmatic children. J Occup Environ Med 2006; 48: 462-469.

101 Smith BJ, Nitschke M, Pilotto LS, et al. Health effects of daily indoor nitrogen dioxide exposure in people with asthma. Eur Respir J 2000; 16: 879-885.

102 van Strien RT, Gent JF, Belanger $\mathrm{K}$, et al. Exposure to $\mathrm{NO}_{2}$ and nitrous acid and respiratory symptoms in the first year of life. Epidemiology 2004; 15: 471-478.

103 Hansel NN, Breysse PN, McCormack MC, et al. A longitudinal study of indoor nitrogen dioxide levels and respiratory symptoms in inner-city children with asthma. Environ Health Perspect 2008; 116: 1428-1432.

104 Garrett MH, Hooper MA, Hooper BM, et al. Respiratory symptoms in children and indoor exposure to nitrogen dioxide and gas stoves. Am J Respir Crit Care Med 1998; 158: 891-895.

105 Melia RJ, Florey Cdu V, Morris RW, et al. Childhood respiratory illness and the home environment. II. Association between respiratory illness and nitrogen dioxide, temperature and relative humidity. Int J Epidemiol 1982; 11: 164-169.

106 Zhao Z, Zhang Z, Wang Z, et al. Asthmatic symptoms among pupils in relation to winter indoor and outdoor air pollution in schools in Taiyuan, China. Environ Health Perspect 2008; 116: 90-97.

107 Neas LM, Dockery DW, Ware JH, et al. Association of indoor nitrogen dioxide with respiratory symptoms and pulmonary function in children. Am J Epidemiol 1991; 134: 204-219.

108 Berwick M, Leaderer BP, Stolwijk JA. Lower respiratory symptoms in children exposed to nitrogen dioxide from unvented combustion sources. Environment International 1989; 15: 369-373.

109 Shima M, Adachi M. Effect of outdoor and indoor nitrogen dioxide on respiratory symptoms in schoolchildren. Int $J$ Epidemiol 2000; 29: 862-870.

110 Samet JM, Lambert WE, Skipper BJ, et al. Nitrogen dioxide and respiratory illnesses in infants. Am Rev Respir Dis 1993; 148: 1258-1265.

111 Sunyer J, Puig C, Torrent $M$, et al. Nitrogen dioxide is not associated with respiratory infection during the first year of life. Int J Epidemiol 2004; 33: 116-120.

112 Belanger K, Triche EW. Indoor combustion and asthma. Immunol Allergy Clin North Am 2008; 28: 507-519.

113 Pilotto LS, Nitschke M, Smith BJ, et al. Randomized controlled trial of unflued gas heater replacement on respiratory health of asthmatic schoolchildren. Int J Epidemiol 2004; 33: 208-214.
114 Holguin F. Traffic, outdoor air pollution, and asthma. Immunol Allergy Clin North Am 2008; 28: 577-588.

115 Simoni M, Baldacci S, Puntoni R, et al. Respiratory symptoms/ diseases and environmental tobacco smoke (ETS) in never smoker Italian women. Respir Med 2007; 101: 531-538.

116 Treyster Z, Gitterman B. Second hand smoke exposure in children: environmental factors, physiological effects, and interventions within pediatrics. Rev Environ Health 2011; 26: 187-195.

117 Delfino RJ, Gong H Jr., Linn WS, et al. Asthma symptoms in Hispanic children and daily ambient exposures to toxic and criteria air pollutants. Environ Health Perspect 2003; 111: 647-656.

118 Koenig JQ, Mar TF, Allen RW, et al. Pulmonary effects of indoorand outdoor-generated particles in children with asthma. Environ Health Perspect 2005; 113: 499-503.

119 Trenga CA, Sullivan JH, Schildcrout JS, et al. Effect of particulate air pollution on lung function in adult and pediatric subjects in a Seattle panel study. Chest 2006; 129: 1614-1622.

120 Ma L, Shima M, Yoda Y, et al. Effects of airborne particulate matter on respiratory morbidity in asthmatic children. J Epidemiol 2008; 18: 97-110.

121 McCormack MC, Breysse PN, Matsui EC, et al. In-home particle concentrations and childhood asthma morbidity. Environ Health Perspect 2009; 117: 294-298.

122 Neas LM, Dockery DW, Ware JH, et al. Concentration of indoor particulate matter as a determinant of respiratory health in children. Am J Epidemiol 1994; 139: 1088-1099.

123 Simoni M, Scognamiglio A, Carrozzi L, et al. Indoor exposures and acute respiratory effects in two general population samples from a rural and an urban area in Italy. J Expo Anal Environ Epidemiol 2004; 14: Suppl. 1, S144-S152.

124 Mendell MJ. Indoor residential chemical emissions as risk factors for respiratory and allergic effects in children: a review. Indoor Air 2007; 17: 259-277.

125 Krzyzanowski M, Quackenboss JJ, Lebowitz MD. Chronic respiratory effects of indoor formaldehyde exposure. Environ Res 1990; 52: 117-125.

126 Rumchev KB, Spickett JT, Bulsara MK, et al. Domestic exposure to formaldehyde significantly increases the risk of asthma in young children. Eur Respir J 2002; 20: 403-408.

127 Smedje G, Norback D, Edling C. Asthma among secondary schoolchildren in relation to the school environment. Clin Exp Allergy 1997; 27: 1270-1278.

128 Garrett MH, Hooper MA, Hooper BM, et al. Increased risk of allergy in children due to formaldehyde exposure in homes. Allergy 1999; 54: 330-337.

129 McGwin G, Lienert J, Kennedy JI. Formaldehyde exposure and asthma in children: a systematic review. Environ Health Perspect 2010; 118: 313-317.

130 Lawrance R. Can training reduce the rural workforce shortage? Aust Fam Physician 2004; 33: 173-174.

131 Norback D, Bjornsson E, Janson C, et al. Asthmatic symptoms and volatile organic compounds, formaldehyde, and carbon dioxide in dwellings. Occup Environ Med 1995; 52: 388-395.

132 Venn AJ, Cooper M, Antoniak M, et al. Effects of volatile organic compounds, damp, and other environmental exposures in the home on wheezing illness in children. Thorax 2003; 58: 955-960.

133 Rumchev K, Spickett J, Bulsara M, et al. Association of domestic exposure to volatile organic compounds with asthma in young children. Thorax 2004; 59: 746-751.

134 Arif AA, Shah SM. Association between personal exposure to volatile organic compounds and asthma among US adult population. Int Arch Occup Environ Health 2007; 80: 711-719.

135 Lehmann I, Thoelke A, Rehwagen M, et al. The influence of maternal exposure to volatile organic compounds on the cytokine secretion profile of neonatal T cells. Environ Toxicol 2002; 17: 203-210.

136 Baiz N, Slama R, Béné MC, et al. Exposure to air pollution before and during pregnancy can induce changes in newborn's cord 
blood lymphocytes involved in allergic response. BMC Pregnancy Childbirth 2011; 11: 1-12.

137 Bornehag CG, Sundell J, Weschler CJ, et al. The association between asthma and allergic symptoms in children and phthalates in house dust: a nested case-control study. Environ Health Perspect 2004; 112: 1393-1397.

138 Carpenter DO, Ma J, Lessner L. Asthma and infectious respiratory disease in relation to residence near hazardous waste sites. Ann NY Acad Sci 2008; 1140: 201-208.

139 Romieu I, Castro-Giner F, Kunzli N, et al. Air pollution, oxidative stress and dietary supplementation: a review. Eur Respir J 2008, 31: 179-196.

140 Casset A, Marchand C, Purohit A, et al. Inhaled formaldehyde exposure: effect on bronchial response to mite allergen in sensitized asthma patients. Allergy 2006; 61: 1344-1350.

141 Hulin M, Annesi-Maesano I. Allergies et asthme chez l'enfant en milieu rural agricole [Allergic diseases in children and farming environment]. Rev Mal Respir 2010; 27: 1195-1220.

142 von Mutius E, Radon K. Living on a farm: impact on asthma induction and clinical course. Immunol Allergy Clin North Am 2008; 28: 631-647.

143 Braun-Fahrlander C, Gassner M, Grize L, et al. Prevalence of hay fever and allergic sensitization in farmer's children and their peers living in the same rural community. SCARPOL team. Swiss Study on Childhood Allergy and Respiratory Symptoms with Respect to Air Pollution. Clin Exp Allergy 1999; 29: 28-34.

144 Remes ST, Koskela HO, Iivanainen K, et al. Allergen-specific sensitization in asthma and allergic diseases in children: the study on farmers' and non-farmers' children. Clin Exp Allergy 2005; 35: 160-166.

145 Schram-Bijkerk D, Doekes G, Douwes J, et al. Bacterial and fungal agents in house dust and wheeze in children: the PARSIFAL study. Clin Exp Allergy 2005; 35: 1272-1278.

146 von Mutius E, Braun-Fahrlander C, Schierl R, et al. Exposure to endotoxin or other bacterial components might protect against the development of atopy. Clin Exp Allergy 2000; 30: 1230-1234.

147 Waser M, Schierl R, von Mutius E, et al. Determinants of endotoxin levels in living environments of farmers' children and their peers from rural areas. Clin Exp Allergy 2004; 34: 389-397.

148 Sudre B, Vacheyrou M, Braun-Fahrlander C, et al. High levels of grass pollen inside European dairy farms: a role for the allergyprotective effects of environment? Allergy 2009; 64: 1068-1073.

149 Riedler J, Braun-Fahrlander C, Eder W, et al. Exposure to farming in early life and development of asthma and allergy: a crosssectional survey. Lancet 2001; 358: 1129-1133.

150 Pfefferle PI, Buchele G, Blumer N, et al. Cord blood cytokines are modulated by maternal farming activities and consumption of farm dairy products during pregnancy: The PASTURE Study. I Allergy Clin Immunol 2010; 125: 108-115.

151 Ege MJ, Mayer M, Normand AC, et al. Exposure to environmental microorganisms and childhood asthma. N Engl J Med 2011; 364: 701-709

152 Lamprecht B, Schirnhofer L, Kaiser B, et al. Farming and the prevalence of non-reversible airways obstruction: results from a population-based study. Am J Ind Med 2007; 50: 421-426.
153 Mastrangelo G, Tartari M, Fedeli U, et al. Ascertaining the risk of chronic obstructive pulmonary disease in relation to occupation using a case-control design. Occup Med (Lond) 2003; 53: 165-172.

154 Lee SA, Adhikari A, Grinshpun SA, et al. Personal exposure to airborne dust and microorganisms in agricultural environments. J Occup Environ Hyg 2006; 3: 118-130.

155 Reboux G, Reiman M, Roussel S, et al. Impact of agricultural pratices on microbiology of hay, silage and flour on Finnish and French farms. Ann Agric Environ Med 2006; 13: 267-273.

156 Schulze A, Van Strien R, Ehrenstein V, et al. Ambient endotoxin level in an area with intensive livestock production. Ann Agric Environ Med 2006; 13: 87-91.

157 Danuser B, Weber C, Kunzli N, et al. Respiratory symptoms in Swiss farmers: an epidemiological study of risk factors. Am J Ind Med 2001; 39: 410-418.

158 Talini D, Monteverdi A, Carrara M, et al. Risk factors for chronic respiratory disorders in a sample of farmers in middle Italy. Monaldi Arch Chest Dis 2003; 59: 52-55.

159 Post W, Heederik D, Houba R. Decline in lung function related to exposure and selection processes among workers in the grain processing and animal feed industry. Occup Environ Med 1998; 55: 349-355.

160 Preller L, Heederik D, Boleij JS, et al. Lung function and chronic respiratory symptoms of pig farmers: focus on exposure to endotoxins and ammonia and use of disinfectants. Occup Environ Med 1995; 52: 654-660.

161 Vogelzang PF, van der Gulden JW, Folgering H, et al. Endotoxin exposure as a major determinant of lung function decline in pig farmers. Am J Respir Crit Care Med 1998; 157: 15-18.

162 Kirychuk SP, Dosman JA, Reynolds SJ, et al. Total dust and endotoxin in poultry operations: comparison between cage and floor housing and respiratory effects in workers. J Occup Environ Med 2006; 48: 741-748.

163 Smit LAM, Heederik D, Doekes G, et al. Exposure-response analysis of allergy and respiratory symptoms in endotoxinexposed adults. Eur Respir J 2008; 31: 1241-1248.

164 Eduard W, Pearce N, Douwes J. Chronic bronchitis, COPD, and lung function in farmers - the role of biological agents. Chest 2009; 136: 716-725.

165 Monso E, Riu E, Radon K, et al. Chronic obstructive pulmonary disease in never-smoking animal farmers working inside confinement buildings. Am J Ind Med 2004; 46: 357-362.

166 Eduard W, Douwes J, Mehl R, et al. Short term exposure to airborne microbial agents during farm work: exposure-response relations with eye and respiratory symptoms. Occup Environ Med 2001; 58: 113-118.

167 Eduard W, Douwes J, Omenaas E, et al. Do farming exposures cause or prevent asthma? Results from a study of adult Norwegian farmers. Thorax 2004; 59: 381-386.

168 Smit L, Heederik D, Doekes G, et al. Occupational endotoxin exposure reduces the risk of atopic sensitization but increases the risk of bronchial hyperresponsiveness. Int Arch Allergy Immunol 2010; 152: 151-158.

169 Schenker MB. Farming and asthma. Occup Environ Med 2005; 62 211-212. 